\title{
Plasma Lipid Transfer Protein as a Determinant of the Atherogenicity of Monkey Plasma Lipoproteins
}

\author{
E. Quinet,* A. Tall,* R. Ramakrishnan," and L. Rudel \\ *Department of Medicine, Columbia University College of Physicians and Surgeons, New York 10032; and Department of Comparative \\ Medicine, Bowman Gray School of Medicine of Wake Forest University, Winston-Salem, North Carolina 27103
}

\begin{abstract}
This study was undertaken to determine potential tissue sources of plasma cholesteryl ester transfer protein (CETP), and to assess the influence of CETP on lipoprotein concentrations and atherosclerosis. In a group of 28 cynomolgus monkeys fed high fat, high cholesterol diets, plasma CETP concentration was strongly correlated with the abundance of CETP mRNA in liver and in adipose tissue, and with the output of CETP in liver perfusates. Plasma CETP concentration showed a strong inverse correlation with HDL cholesterol concentrations $(r=-0.62, P<0.001)$ and a positive correlation with LDL cholesterol concentration $(r=0.54, P<0.005)$ and molecular weight $(r=0.57, P<0.001)$. The extent of coronary artery atherosclerosis was positively correlated with LDL cholesterol concentration and molecular weight, and with plasma CETP concentration. Thus, in monkeys fed an atherogenic diet, individual variation in CETP $m$ RNA abundance in liver and adipose tissue probably plays a major role in the determination of plasma CETP levels. In plasma, CETP influences the distribution of cholesteryl esters between LDL and HDL, and CETP concentration appears to be a key determinant of the relative atherogenicity of the plasma lipoproteins. (J. Clin. Invest. 1991. 87:1559-1566.) Key words: lipid transfer protein • low density lipoprotein • high density lipoprotein • atherosclerosis • dietary fat
\end{abstract}

\section{Introduction}

In humans and in monkeys increased concentrations of LDL $(1,2)$ and reduced concentrations of $\operatorname{HDL}(3,4)$ are risk factors for the development of atherosclerosis. The plasma cholesteryl ester transfer protein (CETP) ${ }^{1}$ catalyzes the transfer of cholesteryl esters from HDL to other lipoproteins (5). Humans with genetic deficiency of CETP have markedly increased HDL as well as reduced LDL (6). Furthermore, low CETP activity has also been associated with the accumulation of larger, cholesteryl ester-enriched HDL subfractions (7-9). However, it is not known to what extent physiological variation of CETP influ-

Address correspondence to Dr. Alan R. Tall, Department of Medicine, Columbia University College of Physicians and Surgeons, 630 West 168th Street, New York, NY 10032.

Received for publication 7 September 1990 and in revised form 7 December 1990.

1. Abbreviation used in this paper: CETP, cholesteryl ester transfer protein.

J. Clin. Invest.

(c) The American Society for Clinical Investigation, Inc. $0021-9738 / 91 / 05 / 1559 / 08 \quad \$ 2.00$

Volume 87, May 1991, 1559-1566 ences lipoprotein concentrations. Plasma CETP has been proposed to be either an antiatherogenic factor, promoting the transfer of cholesteryl ester from HDL to triglyceride-rich lipoproteins as part of the process of reverse cholesterol transport, or as a proatherogenic factor, facilitating accumulation of cholesteryl esters in the atherogenic remnants of triglyceride-rich lipoproteins (5). Humans with CETP deficiency may be protected from atherosclerosis, but the relationship of CETP to atherosclerosis has not been examined systematically (10). Plasma CETP is increased in rabbits fed an atherogenic diet, in association with an increase in liver CETP mRNA (11). These findings suggest that tissue CETP mRNA levels may be an important source of plasma CETP variation. The goals of this study were $(a)$ to determine the relationship of plasma CETP with lipoprotein levels in monkeys fed atherogenic diets; $(b)$ to examine the relationship of plasma CETP with coronary artery atherosclerosis; $(c)$ to determine potential tissue sources of plasma CETP by measuring tissue mRNA levels; and $(d)$ to determine the effects of diet composition (polyunsaturated vs. saturated fat; high vs. low cholesterol) on plasma CETP concentration.

\section{Methods}

Animals, diets, and liver perfusion. Study 1: Male cynomolgus monkeys were fed diets containing $0.2 \mathrm{mg}$ of cholesterol $/ \mathrm{kcal}$ and $40 \%$ of calories as fat for $5 \mathrm{yr}$. Half of the animals $(n=14)$ were fed a diet rich in saturated fat (polyunsaturated to saturated $[\mathrm{P} / \mathrm{S}]$ ratio $=0.3$ ), and half received a diet rich in polyunsaturated fat $(\mathrm{P} / \mathrm{S}=2.2)$. At necropsy, tissues were collected and frozen for storage at $-70^{\circ} \mathrm{C}$. Liver perfusion was performed as described (12). Briefly, isolated livers were perfused with medium consisting of Krebs-Henseleit original Ringer's bicarbonate buffer containing D-glucose, amino acids, insulin, hydrocortisone, streptomycin, penicillin, and washed human erythrocytes at $20 \%$ hematocrit, $\mathrm{pH}$ 7.4. Medium containing $2 \%$ human serum albumin (Cutter Laboratories, Inc., Berkeley, CA) and fatty acid (oleate) was infused at a rate of $0.1 \mu \mathrm{mol} / \mathrm{min} / \mathrm{g}$ while taurocholate was infused at a rate of $0.036 \mathrm{mg} / \mathrm{min}$ to $100 \mathrm{~g}$ liver. A 90 -min period of recirculating perfusion was followed by noncirculating perfusion, to flush the liver free of the original perfusion. Recirculating perfusion was resumed with $\sim 300 \mathrm{ml}$ of fresh media for $4 \mathrm{~h}$. Liver viability criteria were liver color, rate of bile production, rate of oxygen consumption, and linear rate of perfusate cholesterol accumulation. Study 2: Young adult male cynomolgus monkeys ( $5 \mathrm{~kg}$ ) were fed high fat diets containing $40 \%$ of calories as fat, either saturated $(\mathrm{P} / \mathrm{S}=0.3)$ or polyunsaturated $(\mathrm{P} / \mathrm{S}=8.0)$ and cholesterol, either $0.04 \mathrm{mg} / \mathrm{kcal}$ (low cholesterol) or $0.4 \mathrm{mg} / \mathrm{kcal}$ (high cholesterol). Animals were maintained on the diets for $3 \mathrm{yr}$. Liver perfusion was for $4 \mathrm{~h}$ as described above.

Coronary artery intimal area. The heart was removed for morphometric determination of coronary artery intimal area, as described (13). 15 blocks were cut perpendicular to the long axis of the arteries; five serial blocks were cut from each of three coronary arteries (the left circumflex, the left anterior descending, and the right coronary artery). Intimal areas, representing the amount of atherosclerotic plaque seen in cross section of various coronary arteries, were determined by digi- 
tizing the area between the internal elastic lamina and the luminal surface of each coronary artery section (13).

CETP mass, HDL cholesterol, and LDL cholesterol and molecular weight determination. CETP mass and the rate of CETP accumulation in perfusate medium was determined by solid phase competitive RIA (14). HDL and LDL were chromatographically separated from other lipoproteins on agarose columns, and cholesterol was determined by standard methods (15). LDL molecular weight was measured using the agarose column method after isolation of the $d<1.225 \mathrm{~g} / \mathrm{ml}$ lipoproteins from plasma (16). HDL subfractions were separated and quantitated as previously described (17). Apolipoproteins A-I and B were assayed in whole plasma using a noncompetitive ELISA $(18,19)$.

Isolation of cellular $R N A$, probes, and solution hybridization. Total cellular RNA from monkey liver, adipose, and peripheral tissues was prepared by the $\mathrm{LiCl}_{2} /$ urea extraction method (20) and the integrity assessed by agarose/borate gel electrophoresis. In a preliminary experiment a single 2.2-kb mRNA was detected in a Northern blot of monkey liver RNA, using a full-length human CETP cDNA probe. CETP mRNA was quantitated in liver and other tissues of the monkey by RNAse protection assay, using an RNA probe prepared from the human CETP cDNA. An antisense RNA probe (KS+ CETP 726-892) was synthesized using $\left.{ }^{32} \mathrm{P}\right] \mathrm{UTP}$ and hybridized to $25-50 \mu \mathrm{g}$ total cellular RNA at $48^{\circ} \mathrm{C}$ followed by digestion with RNase T2 at $30^{\circ} \mathrm{C}$ for $2 \mathrm{~h}$. Protected fragments were analyzed by denaturing polyacrylamide gel electrophoresis and RNA mass was determined as described previously (11). After hybridization with monkey RNA, the human cRNA probe yielded a nuclease-resistant fragment of the expected molecular weight, confirming complete or nearly complete homology between the human probe and the monkey CETP $m R$ NA sequence, and validating the assay for use with monkey RNA. Apo A-I, apo B, and LDL receptor mRNAs were measured by DNA-excess solution hybridization assays using single stranded cDNA probes prepared from appropriate subclones in bacteriophage M13 as described $(19,21)$.

Statistical analysis. Regression analysis was carried out using the BMDP9R statistical program for all possible regressions (BMDP Statistical Software, Inc., Los Angeles, CA). One animal was excluded from the analysis on the basis of an outlying plasma CETP value. However, the inclusion of this animal did not change any of the major conclusions.

\section{Results}

Abundance of CETP $\mathrm{mRNA}$ in monkey tissues. To determine its major tissue sources in the monkey, the CETP mRNA was quantitated by RNAse protection assay in RNA isolated from the liver and 11 other tissues of two male cynomolgus monkeys. Table I shows the abundance of the CETP mRNA expressed as pg CETP mRNA/ $\mu$ g total RNA. Liver and adipose tissues were found to contain the highest levels of the CETP mRNA. By contrast, muscle, spleen, small intestine, adrenal, and kidney each had less than one twentieth the liver CETP mRNA concentration. Adipose tissue has recently been found to be a major source of CETP mRNA in a variety of mammalian species, including humans (22). In the cynomolgus monkey, omental, perirenal, and subcutaneous fat each had levels of CETP mRNA comparable to liver. To evaluate effects on plasma CETP and lipoprotein concentrations, the abundance of the CETP mRNA was determined in liver and omental adipose tissue in study 1 .

Effect of dietary fat saturation on plasma lipoprotein and CETP parameters (study 1). Plasma lipid, lipoprotein, and apolipoprotein concentrations, various parameters of CETP gene expression, and abundance of some other potentially relevant mRNAs were determined in a group of 28 cynomolgus monkeys fed diets high in fat ( $40 \%$ of calories) and moderately
Table I. CETP MRNA in Liver, Adipose, and Other Tissues of Cynomolgus Monkeys

\begin{tabular}{lcc}
\hline \multicolumn{1}{c}{ Tissue } & CETP mRNA & $\begin{array}{c}\text { Relative amounts of } \\
\text { CETP mRNA }\end{array}$ \\
\hline Liver & $p g / \mu g$ RNA & Percent of liver \\
Perirenal fat & 3.00 & 100 \\
Subcutaneous fat & 4.80 & 160 \\
Omental fat & 1.80 & 59 \\
Spleen & 1.00 & 33 \\
Adrenal & 0.70 & 5 \\
Kidney & 0.06 & 2 \\
Duodenum & 0.07 & 2 \\
Skelelta muscle & $<0.05$ & - \\
Brain & $<0.05$ & - \\
Lung & $<0.05$ & - \\
Testis & $<0.05$ & - \\
\end{tabular}

CETP mRNA was measured in total RNA extracted from the indicated tissues by RNAse protection assay. Total RNA was quantitated by $A_{260 \mathrm{~mm}}$. Tissues from two monkeys were used for each peripheral tissue analysis and values represent the means.

enriched in cholesterol $(0.2 \mathrm{mg} / \mathrm{kcal})$ for $5 \mathrm{yr}$ (Table II). Half of the animals received a diet rich in saturated fat $(\mathrm{P} / \mathrm{S}$ ratio $=0.3)$ and half received a diet rich in polyunsaturated fat $(P / S=2.2)$. The moderate dietary cholesterol content induced a level of hypercholesterolemia in this species comparable to that of humans. Comparing the mean values for animals receiving the two diets, only HDL cholesterol and plasma apo A-I concentrations showed significant differences between the two diet groups, with a $27 \%$ reduction in both measurements on the high polyunsaturated fat diet. Plasma cholesterol, LDL cholesterol, and apoB measurements tended to be lower in the group receiving the high polyunsaturated fat diet, but the differences between the groups were not statistically significant. The concentration of CETP in plasma, the output of CETP in liver perfusates, and the abundance of CETP mRNA in adipose tissue and liver were no different between the two diet groups. In addition, there were no significant differences in the abundance of various liver mRNAs or in the extent of coronary artery atherosclerosis. Despite the lack of difference between the two diet groups, there was considerable variation amongst animals in the various CETP parameters, providing the opportunity to test the hypotheses that plasma CETP level is determined in part by synthesis in liver and adipose tissue, and that variation in plasma CETP influences the distribution of cholesteryl esters between LDL and HDL.

Determinants of plasma CETP concentration. Since there was no difference in CETP parameters between the diet groups, the data for both diets were combined for correlational analysis. There was a strong correlation between liver CETP mRNA abundance and plasma CETP concentration (Fig. $1 A ; r=0.70$, $P<0.001, n=27$ ). Also, there was a weaker but significant relationship between adipose tissue mRNA levels and plasma CETP (Fig. $1 B, r=0.51, P<0.02, n=24$; adipose tissue was not available for analysis of CETP mRNA in three monkeys). One animal was excluded from the analysis because of outlying values for both adipose tissue mRNA abundance $(18 \mathrm{pg} / \mu \mathrm{g}$ 
Table II. Dietary Effects on Plasma Lipoprotein and CETP Parameters

\begin{tabular}{|c|c|c|c|}
\hline Diet & Saturated & Polyunsaturated & Significance \\
\hline & $n=14$ & $n=14$ & $P$ value \\
\hline \multicolumn{4}{|l|}{ Plasma cholesterol } \\
\hline Total $(m g / d l)$ & $309 \pm 116$ & $268 \pm 106$ & NS \\
\hline $\operatorname{LDL}(m g / d l)$ & $222 \pm 95$ & $195 \pm 100$ & NS \\
\hline $\mathrm{HDL}(m g / d l)$ & $59 \pm 20$ & $43 \pm 21$ & 0.05 \\
\hline \multicolumn{4}{|l|}{ Plasma apolipoproteins } \\
\hline Apo A-I $(m g / d l)$ & $184 \pm 41$ & $134 \pm 32$ & 0.001 \\
\hline Apo B $(m g / d l)$ & $205 \pm 59$ & $164 \pm 58$ & NS \\
\hline Apo E $(m g / d l)$ & $11.2 \pm 4.0$ & $11.0 \pm 6.6$ & NS \\
\hline \multicolumn{4}{|l|}{ Apo A-I mRNA $(p g / \mu g$} \\
\hline$R N A)$ & $50 \pm 9$ & $55 \pm 13$ & NS \\
\hline \multicolumn{4}{|l|}{ Apo B mRNA $(p g / \mu g$} \\
\hline$R N A)$ & $145 \pm 79$ & $98 \pm 48^{*}$ & NS \\
\hline \multicolumn{4}{|l|}{ LDL-R mRNA $(p g / \mu g$} \\
\hline$R N A)$ & $1.7 \pm 1.1^{\ddagger}$ & $1.6 \pm 0.7^{\S}$ & NS \\
\hline \multicolumn{4}{|l|}{ CETP } \\
\hline Plasma $(\mu g / m l)$ & $24 \pm 7$ & $27 \pm 14$ & NS \\
\hline \multicolumn{4}{|l|}{ Perfusate $(\mu g / h / 100 g$} \\
\hline liver) & $13.4 \pm 4.6$ & $15.2 \pm 11.6$ & NS \\
\hline \multicolumn{4}{|l|}{ Hepatic mRNA $(p g / \mu g$} \\
\hline$R N A)$ & $1.5 \pm 0.6$ & $1.8 \pm 1.0$ & NS \\
\hline Fat mRNA $(p g / \mu g R N A)$ & $1.3 \pm 1.5^{\ddagger}$ & $1.9 \pm 1.4^{\ddagger}$ & NS \\
\hline $\begin{array}{l}\text { Coronary intimal area } \\
\left(\mathrm{mm}^{2}\right)\end{array}$ & $0.57 \pm 0.48$ & $1.02 \pm 1.27$ & NS \\
\hline
\end{tabular}

Values are mean \pm SD. All animals were fed experimenal diets for $5 \mathrm{yr}$. ${ }^{*} n=11 ;{ }^{\ddagger} n=12 ;{ }^{\S} n=13$.

RNA) and plasma CETP concentration ( $65 \mu \mathrm{g} / \mathrm{ml})$. Inclusion of this animal caused a disproportionate increase (to 0.8 ) in the correlation between plasma CETP and fat CETP mRNA. No correlation was found between liver and adipose tissue mRNA levels. Multiple regression analysis showed that both liver and adipose tissue mRNA levels were independently and significantly correlated with plasma CETP concentration ( $y=11.3$ $+6.3 x_{1}+1.6 x_{2} ; y$ indicates plasma CETP $[\mu \mathrm{g} / \mathrm{ml}], x_{1}$ indicates liver CETP mRNA [pg/ $\mu \mathrm{g}$ RNA], $x_{2}$ indicates fat CETP mRNA [pg/ $\mu \mathrm{g}$ RNA]; $n=24, R^{2}=0.65, P_{1}<0.001$, and $P_{2}$ $<0.05]$ ). These data suggest that both liver and, to a lesser extent, adipose tissue, are significant sources of plasma CETP.

To evaluate further the contribution of hepatic CETP production to plasma CETP, the output of CETP in liver perfusates was determined. Hepatic CETP mRNA abundance was highly correlated with the output of CETP in liver perfusates (Fig. $2 A, r=0.67, P<0.01$ ). In turn, hepatic output of CETP was highly correlated with plasma CETP concentration (Fig. 2 $B, r=0.76, P<0.001)$. Although the data in Fig. $2 B$ are shown as a linear regression analysis, the data could also be fitted by a curvilinear relationship, with lesser increases in plasma CETP concentration as the liver output of CETP rises above $\sim 10$ $\mu \mathrm{g} / \mathrm{h} / 100 \mathrm{~g}$. These correlations strongly suggest that liver CETP mRNA abundance and the output of liver CETP are major factors determining plasma CETP concentration.

Relationship of CETP with plasma lipoprotein and apolipoprotein concentrations. Among all animals, there was a striking inverse relationship between plasma CETP concentration and plasma HDL cholesterol (Fig. $3 A ; r=-0.62, n=27, P$ $<0.001$ ); similar inverse correlations were found in both diet groups (not shown). Analysis of HDL subfractions indicated that the strongest correlations occurred between plasma CETP and the larger HDL subclasses (17); plasma CETP was inversely correlated with $\mathrm{HDL}_{2 \mathrm{a}}$ and $\mathrm{HDL}_{3 \mathrm{a}}$ cholesterol, $r$ $=-0.67$ and -0.70 , respectively, $P<0.0005$. By contrast, $\mathrm{HDL}_{3 \mathrm{~b}}$ and $\mathrm{HDL}_{3 \mathrm{c}}$, showed correlation coefficients of -0.36 and -0.09. Plasma CETP was also inversely correlated with the plasma concentration of the major HDL protein, apolipoprotein A-I, (Fig. $3 B, r=-0.43, P<0.05$ ). The abundance of apo A-I mRNA in liver is an important determinant of differences in plasma apo A-I concentration in different species of monkey (21). However, there was no correlation between liver apo A-I mRNA abundance and HDL cholesterol (Fig. $3 C, n=27$ ) or plasma apo A-I when individual cynomolgus monkeys were compared. Also, the total secretion of cholesterol by the liver, an indicator of the general level of lipoprotein secretion, was not related to plasma HDL cholesterol (Fig. $3 \mathrm{D}$ ) or apo A-I concentrations. Individual monkeys showed a significant inverse correlation between HDL and LDL cholesterol concentration ( $r=-0.58, P<0.002$; not shown).

A significant positive relationship was found between concentrations of plasma CETP and LDL cholesterol (Fig. $4 \mathrm{~A} ; \mathrm{r}$ $=0.54, n=27, P<0.005)$ and between plasma CETP concentration and LDL molecular weight (Fig. $4 B ; r=0.57, P$

A

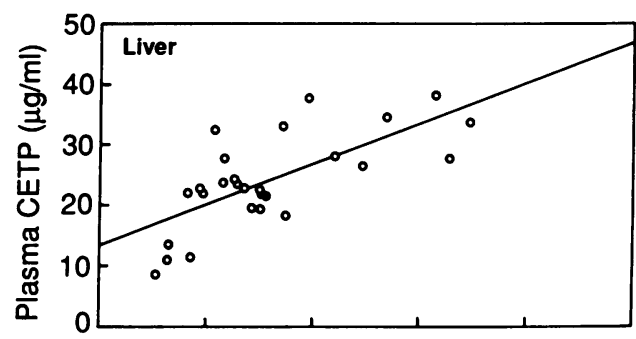

B

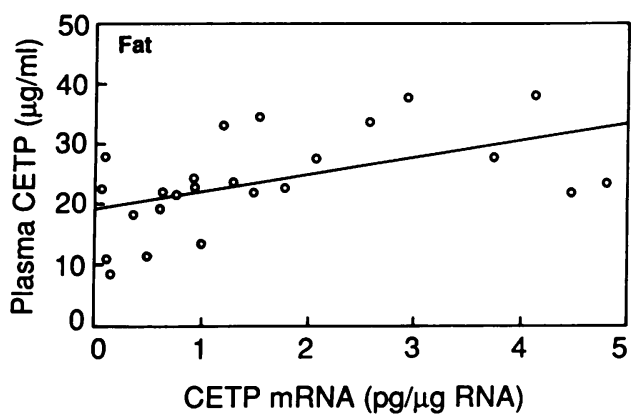

Figure 1. Correlation between hepatic or omental fat mRNA abundance and plasma CETP concentrations. Data points represent individual cynomolgus monkeys fed one of two atherogenic diets containing $0.2 \mathrm{mg} / \mathrm{kcal}$ cholesterol and $40 \%$ of calories as fat. The data for the two diets are combined since there was no significant difference in the CETP mean response on either diet. CETP mRNA was quantitated by RNase protection assay in $25-50 \mu \mathrm{g}$ of total RNA isolated from either monkey liver $(n=27)$ or adipose tissues $(n=24)$. Plasma CETP was measured by radioimmunoassay and was correlated with the mass of CETP mRNA. $(A)$ Comparison of liver mRNA and plasma CETP, $r=0.70, P<0.001$. (B) Comparison of adipose mRNA and plasma CETP, $r=0.51, P<0.02$. 

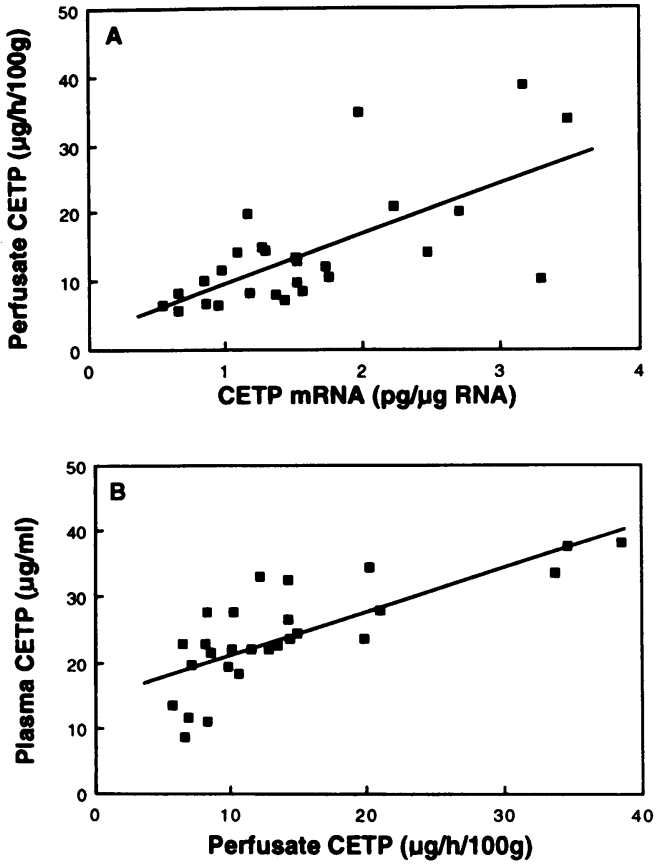

Figure 2. Relationship of liver perfusate CETP secretion rate and hepatic CETP mRNA abundance $(A)$ and liver perfusate CETP secretion rate and plasma CETP concentration $(B)$. The CETP secretion rates are shown for 27 individual monkeys, measured during $4 \mathrm{~h}$ of liver perfusion and normalized for a $100-\mathrm{g}$ liver. The correlation coefficients for the data shown were $r=0.67, P<0.01(A)$; and $r=0.76$, $P<0.001(B)$.

$<0.001, n=27$ ). Also, CETP was positively correlated with plasma apo B concentration (Fig. $4 C ; r=0.47, P<0.02$ ). Other variables that might potentially influence $L D L$ concentrations (the output of cholesterol and apo B in liver perfusates, and liver LDL receptor mRNA levels) showed no significant correlations with plasma LDL cholesterol $(r$ values $=0.20$, 0.17 , and 0.00 , respectively) or apo B concentrations. The data for LDL receptor mRNA abundance is shown in Fig. $4 \mathrm{D}$. Similarly, in multiple regression analysis, the addition of each of these variables to plasma CETP did not significantly improve the multiple correlation for LDL cholesterol concentration. These data suggest that plasma CETP concentration may be an important determinant of the amount of cholesterol transported in LDL.

Relationship of CETP with the extent of coronary artery atherosclerosis. Plasma lipoprotein and CETP concentrations were correlated with the extent of coronary artery atherosclerosis. The amount of coronary artery intimal thickening was determined by morphometric assessment of coronary artery intimal area at necropsy. For each animal, the mean intimal area was determined for five cross-sections on each of three coronary arteries (left anterior descending, left circumflex, and right coronary artery). The response of individual animals was highly variable, with mean \pm SD intimal areas ranging from $0.0076 \pm 0.0146$ to $3.6401 \pm 2.3529 \mathrm{~mm}^{2}$ (polyunsaturated group) and from $0.0018 \pm 0.0065$ to $1.5443 \pm 0.5883 \mathrm{~mm}^{2}$ (saturated group). In view of the nonnormal distribution of this data, the mean values for coronary artery intimal area were log-transformed prior to correlational analysis.

The major correlates of coronary artery atherosclerosis are shown in Fig. 5. Plasma LDL cholesterol concentration was strongly correlated with the extent of atherosclerosis $(r=0.80$, $n=28, P<0.0001$ ). Other measurements reflecting LDL mass (apo B levels, total plasma cholesterol, and LDL molecular weight) were significantly but not as strongly correlated with coronary artery intimal area. Plasma CETP concentration also showed a strong, significant positive correlation with coronary artery intimal area (Fig. $4 B, r=0.58, P<0.001$ ). HDL cholesterol levels showed a weak, marginally significant inverse relationship with coronary intimal area (Fig. $4 C, r=-0.40, P$ $=0.05$ ). In multiple regression analysis, only LDL cholesterol appeared as an independent variable significantly correlated with coronary artery atherosclerosis. Specifically, the addition of plasma CETP concentration and HDL cholesterol did not significantly change the multiple $R$ value derived from LDL cholesterol alone. This analysis suggests that the correlation
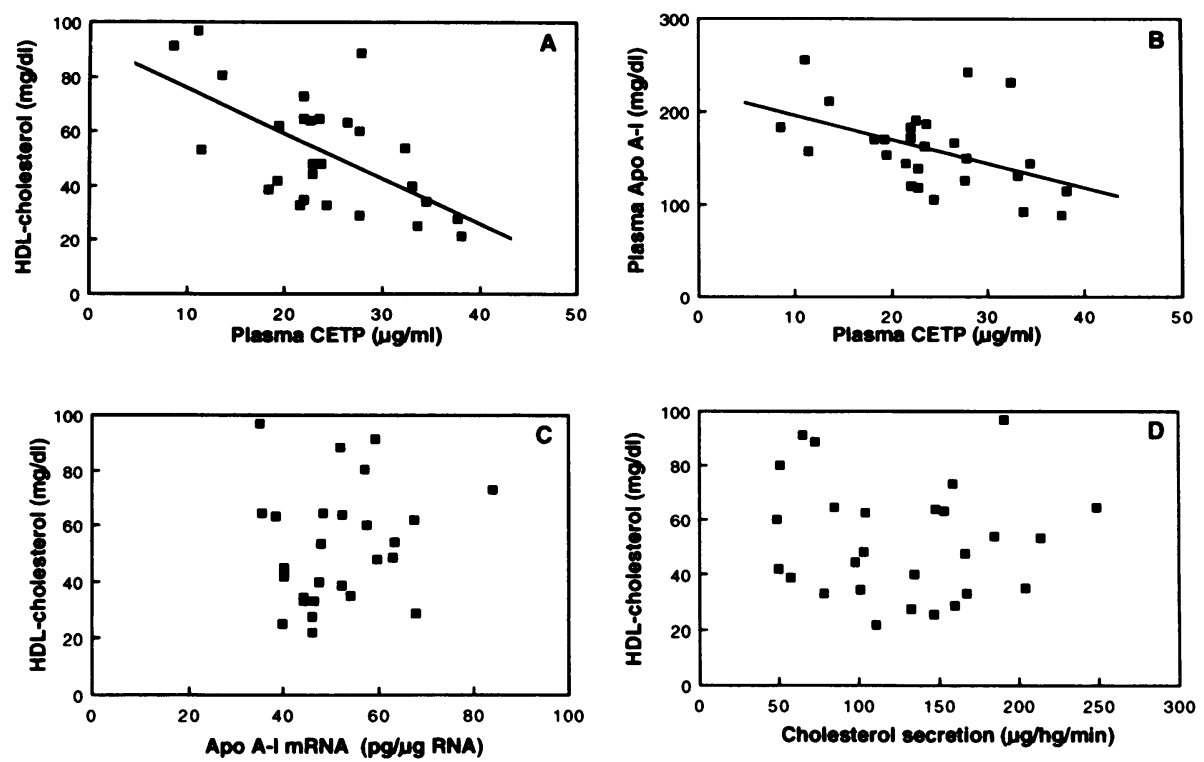

Figure 3. Relationship of plasma CETP with HDL cholesterol concentration $(A)$ and plasma apo A-I concentration $(B)$, and of HDL cholesterol with apo A-I mRNA abundance $(C)$ liver cholesterol secretion rate $(D)$. HDL cholesterol was determined by standard methods subsequent to HDL separation chromatographically on agarose columns. CETP mass was determined by solid phase competitive RIA. The correlation coefficients for this data were $r=-.062, P$ $<0.001(A)$ and $r=-0.43, P<0.05(B)$. There was no significant relationship between HDL cholesterol and either hepatic apo A-I mRNA abundance $(C)$ or between HDL cholesterol and liver cholesterol secretion rates $(D)$. 

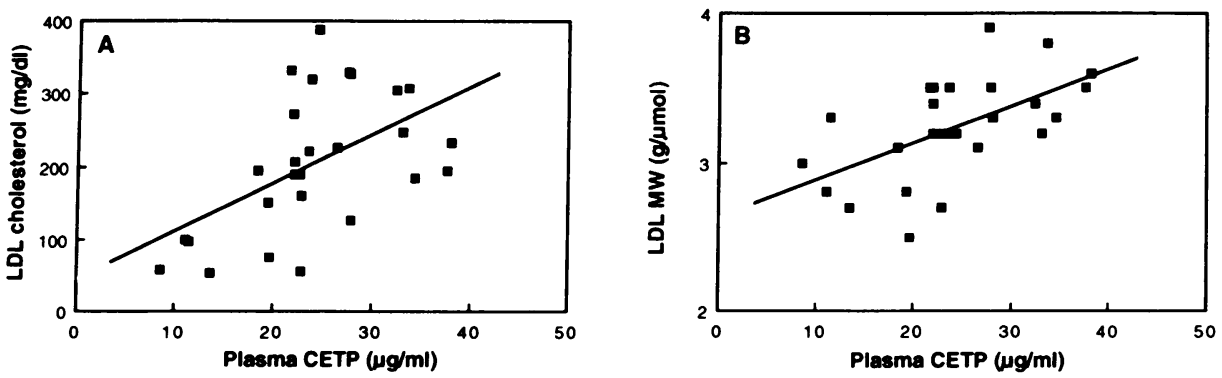

Figure 4. Relationship between plasma CETP concentration and plasma LDL cholesterol concentration $(A)$, LDL molecular weight $(B)$, and plasma apo B concentration $(C)$, and between LDL receptor mRNA abundance and plasma LDL cholesterol concentration $(D)$. The correla-
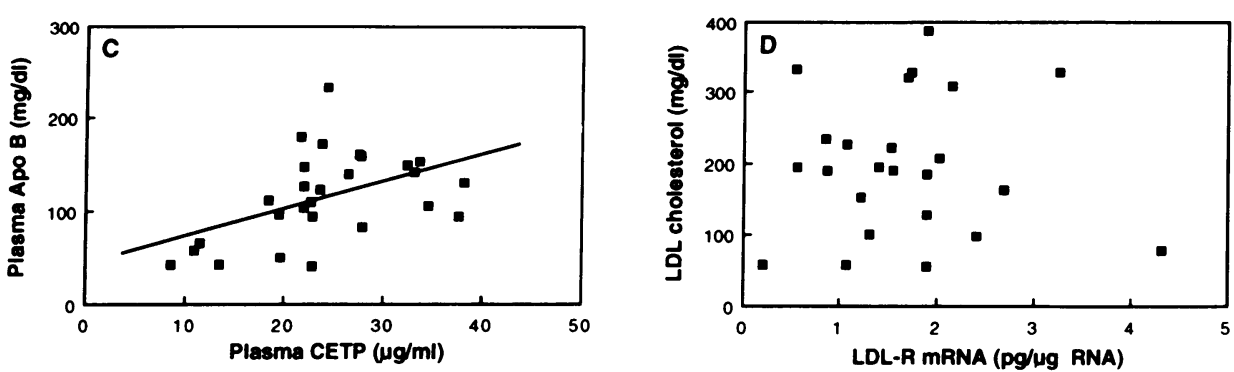

tion coefficients were $r=0.54, P$

$<0.005, n=27(A), r=0.57, P$ $<0.001(B), r=0.47, P<0.02(C)$, and $r=0.08(D)$. LDL receptor mRNA was not correlated with LDL cholesterol $(n=24)$. LDL cholesterol was determined by standard methods following chromatographic separation on agarose columns and LDL molecular weight was determined by the agarose column chromatography.

between CETP and coronary atherosclerosis reflects the association of CETP and LDL cholesterol levels, and that plasma CETP concentration does not have independent effects on atherosclerosis in this experimental model.

Diet-induced changes in CETP and HDL cholesterol (study 2). In the study described above there was no difference in plasma CETP levels in animals receiving the two different types of dietary fat. All animals received the same amount of dietary cholesterol. Determination of plasma CETP concentration in eight cynomolgus monkeys receiving monkey chow (nonsimultaneous control animals) showed a mean plasma CETP concentration of $15 \pm 3 \mathrm{mg} / \mathrm{dl}$, suggesting that plasma CETP concentration was increased $\sim 1.7$-fold as a result of the high fat, high cholesterol diet (Table II). To determine if these changes were primarily due to the increase in dietary cholesterol or in dietary fat content, CETP parameters were determined in four small groups of monkeys fed high fat diets (high polyunsaturated fat or high saturated fat) at two levels of dietary cholesterol (study 2). As in study 1 , there was no difference in response between the animals receiving high saturated or high polyunsaturated fat even when the degree of polyunsaturation was exaggerated (not shown). However, when the data were analyzed according to the cholesterol content of the diet, there were marked differences in plasma CETP and HDL cholesterol concentrations (Table III). In the high cholesterol group plasma CETP concentration and hepatic output of CETP were approximately twice that in the low cholesterol group. There was a marked reduction in HDL cholesterol concentration in the high cholesterol group, compared with the low cholesterol group. Analysis of hepatic CETP mRNA was attempted, but several of the samples were found to be degraded (as assessed by analysis of RNA in borate-agarose gels), and the data was not considered reliable. Correlational analysis showed a significant inverse relationship between plasma CETP concentration and HDL cholesterol $(r=-0.51, P$ $<0.05, n=17$ ) in the animals in this study. The analysis of data in study 2 , combined with the data from control animals, suggests that the increase in dietary cholesterol is the major factor determining the increase in plasma CETP concentration in response to an atherogenic diet. Also, the data suggest that the decrease in HDL cholesterol in response to increased dietary cholesterol may be due in part to increased plasma CETP concentration.

\section{Discussion}

The major goals of this study were to relate variation in plasma CETP levels to plasma lipoprotein concentrations and atherosclerosis in a group of cynomolgus monkeys that had been fed moderately atherogenic diets for a period of five years. There were striking inverse correlations of plasma CETP with HDL cholesterol and apo A-I and positive correlations with LDL. cholesterol and apo B, suggesting that CETP may be an important determinant of individual variability in HDL and LDL levels. The potential relevance of CETP in this regard was highlighted by the fact that several other potential regulatory factors (liver LDL receptor mRNA, apo A-I mRNA, and apo B mRNA) bore no relationship with LDL or HDL cholesterol measurements. The plasma CETP concentration was also found to have a positive relationship with coronary artery atherosclerosis, apparently reflecting effects of CETP on LDL cholesterol levels. The plasma CETP levels, in turn, were strongly related to CETP mRNA abundance in liver and adipose tissue, and to the output of CETP in liver perfusates. Thus, the individual animal's liver and adipose tissue CETP mRNA levels, probably determined by genetic and dietary factors (11), may ultimately influence plasma lipoprotein levels and atherogenesis.

The simplest explanation for the opposite correlations of CETP mass with LDL and HDL cholesterol is that CETP catalyzes the transfer of cholesteryl esters from HDL to LDL or its precursors, and thereby influences the steady-state concentration of cholesterol (mostly cholesteryl ester) carried in each particle. Supporting this idea was the finding that in individual animals, there was an inverse relationship between HDL and LDL cholesterol concentration. A number of earlier studies (summarized in [5]) have suggested that the rate of transfer of cholesteryl ester from HDL to other lipoproteins is a determinant of plasma HDL concentration. However, the rate of cho- 

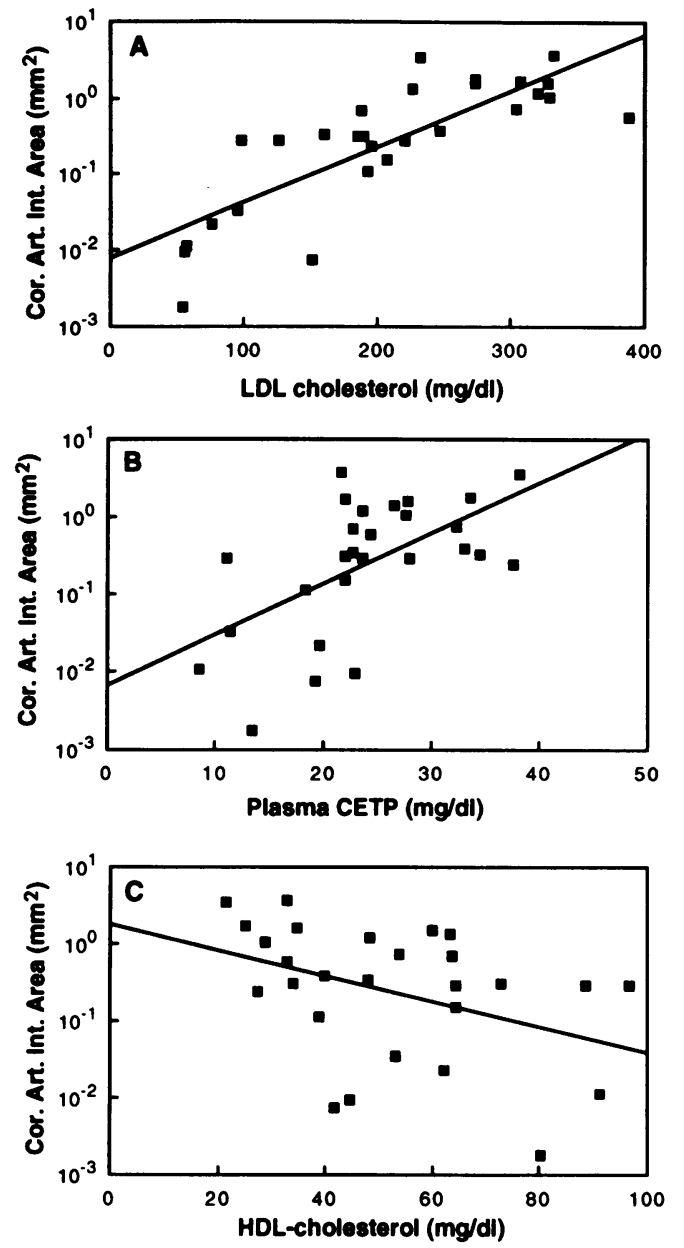

Figure 5. Relationship of coronary artery intimal area and plasma LDL cholesterol concentration $(A)$, plasma CETP concentration $(B)$, and plasma HDL cholesterol concentration $(C)$. $(A)$ Positive relationship of intimal area with LDL cholesterol concentration $(r=0.80$, $P<0.0001)$. (B) Positive relationship between intimal area and plasma CETP concentration $(r=0.58, P<0.001)$. $(C)$ Negative relationship of HDL cholesterol with intimal area $(r=-0.40, P<0.05)$ The extent of coronary artery atherosclerosis was determined by morphometric measurement of intimal areas at necropsy for the 27 individual animals. The data were log transformed before correlational analysis due to the nonnormal distribution.

lesteryl ester transfer between lipoproteins was thought to be largely determined by the level of plasma triglycerides (23). Our findings, as well as other recent data on families with genetic CETP deficiency (10), imply that individual variability in plasma CETP concentration influences the efficiency of the transfer process.

In addition to the apparent effect of CETP on the amount of cholesterol transported per particle (i.e., LDL molecular weight), there was also a correlation of CETP with apo B concentration (Fig. 4), suggesting that CETP might influence the number of LDL particles in plasma. A similar finding has been made in families with genetic CETP deficiency (10). The data in Fig. 3 show a difference in HDL cholesterol concentration of $\sim 60 \mathrm{mg} / \mathrm{dl}$, comparing animals at the extremes of plasma CETP concentration. In Fig. 4 , the difference in LDL cholesterol concentration at the extremes of CETP is $\sim 200 \mathrm{mg} / \mathrm{dl}$.
This indicates that the major part of the apparent effect of CETP on LDL cholesterol cannot be attributed to a simple transfer of cholesterol from HDL. In fact, the decrement in HDL cholesterol $(60 \mathrm{mg} / \mathrm{dl})$ as CETP concentration rises (Fig. 2) approximates the increase in cholesterol mass in LDL attributable to a molecular weight increase from $\sim 2.75$ to $3.75 \mathrm{~g} /$ $\mu$ mol (Fig. 3), assuming a constant number of LDL particles. Thus, the CETP-mediated transfer of cholesteryl esters from HDL to LDL may account for the increase in molecular weight of LDL as the plasma CETP concentration rises from 10 to 35 $\mu \mathrm{g} / \mathrm{ml}$. The other two thirds of the increase in LDL cholesterol apparently results from an increase in LDL particle number. Plasma CETP concentration could also affect the number of LDL particles in plasma, either by influencing the formation or catabolism of LDL. Previously it has been suggested that CETP may influence the apo E content of LDL precursor particles, thereby affecting their rate of removal by the liver $(10,24)$. Alternatively, LDL particle number and plasma CETP concentration may both be responding to a third factor. For example, the increased dietary cholesterol could cause both downregulation of $L D L$ receptors in the liver, and also an increase in hepatic CETP mRNA, resulting in a spurious correlation between plasma CETP and LDL concentrations. However, several candidate "third factors," such as liver LDL receptor mRNA, liver apo B mRNA, or total cholesterol output by the liver, failed to show any correlation with LDL cholesterol levels. Thus, the hypothesis that plasma CETP concentration influences LDL particle number remains viable.

The results of these monkey studies may be partly applicable to humans. Similar correlations between CETP and HDL and LDL cholesterol concentrations have been observed in families with genetic CETP deficiency $(6,10)$. In human studies the strongest inverse correlations are noted between CETP and HDL-2 cholesterol levels $(6,10)$, as also noted in this study, whereas correlations with total HDL cholesterol are weaker (10) or nonexistent (14). This could represent a species difference or the fact that the measurements made in human beings have been made without the dietary or environmental control available for monkeys. Several factors influencing HDL cholesterol concentrations in humans, such as obesity or hepatic lipase activity, are absent in the monkey studies, since the monkeys are not obese and also have uniformly low hepatic lipase

Table III. Effects of High Cholesterol vs. Low Cholesterol Diets on Plasma Cholesterol Concentration, Hepatic CETP MRNA Abundance, and CETP Concentrations in Plasma and Liver Perfusates

\begin{tabular}{cccccc}
\hline & \multicolumn{2}{c}{ Plasma cholesterol } & & \multicolumn{2}{c}{ CETP } \\
\cline { 2 - 3 } \cline { 5 - 6 } Diet & Total & HDL & & Perfusate & Plasma \\
\hline & $m g / d l$ & $m g / d l$ & & $\mu g / h / 100 g$ & $\mu g / m l$ \\
$\begin{array}{c}\text { Low cholesterol } \\
(n=7)\end{array}$ & $170 \pm 8$ & $63 \pm 6$ & & $12 \pm 2^{*}$ & $15 \pm 2$ \\
$\begin{array}{c}\text { High cholesterol } \\
(n=10)\end{array}$ & $360 \pm 15$ & $30 \pm 3$ & & $18 \pm 3^{*}$ & $28 \pm 3$ \\
$P$ value & $<0.0001$ & $<0.0001$ & & NS & $<0.01$ \\
\hline
\end{tabular}

All values represent means \pm SEM. $n$, number of monkeys per group; ${ }^{*} n, 6 ;{ }^{*} n, 7$. 
activity (25). To discern effects of CETP in human cross-sectional studies, it may be necessary to measure several covariates also influencing HDL cholesterol concentrations. Correlation of CETP with LDL cholesterol may be particularly clearly seen in monkeys, because they have very low levels of VLDL (1-2\% of total plasma cholesterol) (25); VLDL may also act as acceptors of HDL cholesteryl ester in humans. In addition, the monkeys all received identical cholesterol-rich diets, which result in downregulation of hepatic LDL receptors (19), perhaps diminishing this factor as a source of variation in LDL. In human hyperlipidemia, CETP might promote accumulation of cholesteryl esters in either VLDL and/or LDL, depending on which lipoprotein class is increased as a result of an underlying metabolic derangement.

As in an earlier study in rabbits (11), liver CETP mRNA content was found to be correlated with plasma CETP concentration. These findings were extended in this investigation by showing an even stronger correlation between liver perfusate CETP concentration and plasma CETP (Fig. 2), establishing liver CETP output as the major determinant of plasma CETP concentration. In addition, adipose tissue CETP mRNA, recently found to be an abundant source of CETP mRNA in a variety of mammalian species (22), was shown to make a smaller but independent contribution to plasma CETP levels. The rabbit studies (7) indicated a threefold increase in liver CETP mRNA in response to a high cholesterol, high fat diet. Our ongoing studies in another monkey species (African green) show an increase in liver CETP mRNA when changing from a chow to a high cholesterol, high fat diet (unpublished). Thus, it is probable that increases in liver CETP mRNA account at least in part for the increase in plasma CETP noted in this study in which we have compared cynomolgus monkeys fed high cholesterol, high fat diets (mean plasma CETP $=27 \mu \mathrm{g} / \mathrm{ml}$ ) with those receiving high fat alone (CETP $=15 \mu \mathrm{g} / \mathrm{ml})$, or with nonsimultaneous control monkeys receiving chow (CETP $=15 \mu \mathrm{g} / \mathrm{ml}$ ). The analysis of additional monkeys receiving different diets (Table III) confirmed the lack of effect of dietary fat saturation on plasma CETP concentration, and indicated a strong effect of dietary cholesterol on plasma CETP. These studies also suggest the conclusion that the decrease in plasma HDL cholesterol due to increased dietary cholesterol (in cynomolgus monkeys) may be in part mediated by an increase in plasma CETP concentration.

A major novel finding of this study was the significant positive relationship between plasma CETP concentration and coronary artery atherosclerosis (Fig. $5 \mathrm{~B}$ ). Combined with recent information suggesting longevity and lack of atherosclerosis in humans with genetic CETP deficiency (10) these data raise the possibility that CETP may enhance the development of atherosclerosis in humans or monkeys receiving atherogenic diets. Multivariate analysis suggested that the positive correlation of CETP with atherosclerosis was due to its relationship with LDL cholesterol. Thus, the plasma CETP concentration, which appears to be determined largely by CETP mRNA levels in liver and adipose tissue, seems to be a major determinant of the atherogenicity of the plasma lipoproteins, probably because CETP transfers cholesteryl esters from nonatherogenic HDL to atherogenic LDL, and also because CETP may influence LDL particle number. However, it must be considered as a possibility that plasma CETP has no effect on LDL or atherosclerosis, and that the association between these variables reflects a com- mon relationship with a confounding variable, not yet identified. Nonetheless, it is most unlikely that CETP has a beneficial effect, promoting the removal of cholesterol from atheromata (5) in the present experimental setting.

The overall role of CETP in cholesterol homeostasis remains fairly obscure. There is some evidence that CETP enhances the return of cholesterol from plasma to the liver (26); also, the high level of CETP mRNA in tissues containing lipoprotein lipase (22) raises the possibility that CETP may help to redistribute cholesterol deposited in adipose tissue or muscle during lipolysis of dietary lipoproteins. Thus, CETP may participate in a process of reverse cholesterol transport or perhaps, more generally, in the redistribution of cholesterol between tissues. The positive correlation of plasma CETP concentration with atherosclerosis (Fig. 5 B) could indicate that CETP has redistributed cholesterol from some tissues (e.g., small blood vessels in adipose tissue and muscle where lipolysis occurs) to LDL and then into coronary arteries. In this sense CETP may participate in a cholesterol redistribution system which in the presence of an atherogenic diet promotes the development of atherosclerosis.

\section{Acknowledgments}

This research was supported by National Institutes of Health grants HL-43165, HL-14164, and HL-24736.

\section{References}

1. Gordon, T., W. P. Castelli, M. C. Hjortland, W. B. Kannel, and T. R. Dawber. 1977. Predicting coronary heart disease in middle-aged and older persons. JAMA (J. Am. Med. Assoc.) 238:497-499.

2. Rudel, L. L., M. G. Bond, and B. C. Bullock. 1985. LDL heterogeneity and arteriosclerosis in nonhuman primates. Ann. NY Acad. Sci. 454:248-253.

3. Gordon, T., W. P. Castelli, M. C. Hjortland, W. B. Kannel, and T. R. Dawber. 1977. High density lipoprotein as a protective factor against coronary heart disease. JAMA (J. Am. Med. Assoc.) 62:707-714.

4. McGill, H. C., Jr., C. A. McMahan, A. W. Kruski, and G. E. Mott. 1981 Relationship of lipoprotein cholesterol concentration to experimental atherosclerosis in baboons. Arteriosclerosis. 1:3-12.

5. Tall, A. R. 1986. Plasma lipid transfer proteins. J. Lipid Res. 27:361-367.

6. Brown, M. L., A. Inazu, C. B. Hesler, L. B. Agellon, C. Mann, M. E. Whitlock, Y. L. Marcel, R. W. Milne, J. Koizumi, H. Mabuchi, R. Takeda, and A. R. Tall. 1989. Molecular basis of lipid transfer protein deficiency in a family with increased high density lipoproteins. Nature (Lond.). 342:448-451.

7. Koizumi, J., H. Mabuchi, A. Yoshimura, I. Michishita, M. Takeda, H. Itoh, Y. Sakai, T. Sakai, D. Ueda, and R. Takeda. 1985. Deficiency of serum cholesteryl ester transfer activity in patients with familial hyperalphalipoproteinaemia. Atherosclerosis. 58:175-186.

8. Kurasawa, T., S. Yokoyama, Y. Miyake, T. Yamamura, and A. Yamamoto. 1985. Rate of cholesteryl ester transfer between high and low density lipoproteins in human serum and a case with decreased transfer rate in association with hyperalphalipoproteinemia. J. Biochem. (Tokyo). 98:1499-1508.

9. Kushwaha, R. S., D. L. Rainwater, M. C. Williams, G. S. Getz, and H. C. McGill, Jr. 1990. Impaired plasma cholesteryl ester transfer with accumulation of larger high density lipoproteins in some families of baboons (Papio sp.). J. Lipid Res. 31:965-973.

10. Inazu, A., M. L. Brown, C. B. Hesler, L. B. Agellon, J. Koizumi, K. Takata, Y. Maruhama, H. Mabuchi, and A. R. Tall. 1990. Increased high-density lipoprotein levels caused by a common cholesteryl ester transfer protein gene mutation. N. Engl. J. Med. 323:1234-1238.

11. Quinet, E. M., L. B. Agellon, P. A. Kroon, Y. L. Marcel, Y. C. Lee, M. E. Whitlock, and A. R. Tall. 1990. Atherogenic diet increases cholesteryl ester transfer protein messenger RNA levels in rabbit liver. J. Clin. Invest. 85:357-363.

12. Parks, J. S., F. L. Johnson, M. D. Wilson, and L. L. Rudel. 1990. Fish oil decreases hepatic cholesteryl ester secretion but not apo B secretion in African green monkeys. J. Lipid Res. 31:455-466.

13. Clarkson, T. B., M. B. Bond, B. C. Bullock, and C. A. Marzetta. 1981. A study of atherosclerosis regression in Macaca mulatta. IV. Changes in coronary arteries from animals with atherosclerosis induced for 19 months and then re- 
gressed for $\mathbf{2 4}$ or $\mathbf{4 8}$ months at plasma cholesterol concentrations of 300 or 200 mg/dl. Exp. Mol. Pathol. 34:345-368.

14. Marcel, Y. L., R. McPherson, M. Hogue, H. Czarnecka, Z. Zawadzki, P. K. Weech, M. E. Whitlock, A. R. Tall, and R. W. Milne. 1990. Distribution and concentration of cholesteryl ester transfer protein in plasma of normolipemic subjects. J. Clin. Invest. 85:10-17.

15. Rudel, L. L., J. A. Lee, M. D. Morris, and J. M. Felts. 1974. Characterization of plasma lipoproteins separated and purified by agarose-column chromatography. Biochem. J. 139:89-95.

16. Rudel, L. L., L. L. Pitts, and C. A. Nelson. 1977. Characterization of plasma low density liproteins of nonhuman primates fed dietary cholesterol. $J$. Lipid Res. 18:211-222.

17. Babiak, J., F. T. Lindgren, and L. L. Rudel. 1988. Effects of saturated and polyunsaturated dietary fat on the concentrations of HDL subpopulations in African green monkeys. Arteriosclerosis. 8:22-32.

18. Koritnik, D. L., and L. L. Rudel. 1983. Measurement of apolipoprotein A-I concentration in nonhuman primate serum by enzyme-linked immunosorbent assay (ELISA). J. Lipid Res. 24:1639-1645.

19. Sorci-Thomas, M., M. D. Wilson, F. L. Johnson, D. L. Williams, and L. L. Rudel. 1989. Studies on the expression of genes encoding apolipoproteins B100 and B48 and the low density lipoprotein receptor in non-human primates. J. Biol. Chem. 264:9039-9045.

20. Auffray, C., and F. Rougeon. 1980. Purification of mouse immunoglobulin heavy-chain messenger RNAs from total myeloma tumor RNA. Eur. J. Biochem. 107:303-314.
21. Sorci-Thomas, M., M. M. Prack, N. Dashti, F. Johnson, L. L. Rudel, and D. L. Williams. 1988. Apolipoprotein (apo) A-I production and mRNA abundance explain plasma apo A-I and high density lipoprotein differences between two non-human primate species with high and low suseptibilities to diet-induced hypercholesterolemia. J. Lipid Res. 30:1397-1403.

22. Jiang, X. C., E. Quinet, L. B. Agellon, S. A. Shelanski, and A. R. Tall 1990. Circulation. 82(Suppl. III):557. (Abstr.)

23. Deckelbaum, R. J., T. Olivecrona, and S. Eisenberg. 1984. Plasma lipoproteins in hyperlipidemia: roles of neutral lipid exchange and lipase. In Treatment of Hyperlipidemia. L. A. Carlson and A. G. Olsson, editors. Raven Press Ltd., New York. 85-93.

24. Bisgaier, C. L., M. V. Siebenkas, C. B. Hesler, T. L. Swenson, C. B. Blum Y. L. Marcel, R. W. Milne, R. M. Glickman, and A. R. Tall. 1989. Effect of a neutralizing monoclonal antibody to cholesteryl ester transfer protein on the redistribution of apoliproteins A-IV and E among human lipoproteins. J. Lipid Res. 30:1025-1031.

25. Rudel, L. L., and R. J. Star. 1990. Species, diet, and gender differences in plasma postheparin lipolytic activities in nonhuman primates: relationships with plasma lipids and high density lipoproteins. Arteriosclerosis. 10:350-357.

26. Whitlock, M. E., T. L. Swenson, R. Ramakrishnan, M. T. Leonard, Y. L. Marcel, R. W. Milne, and A. R. Tall. 1989. Monoclonal antibody inhibition of cholesteryl ester transfer protein activity in the rabbit. Effects on lipoprotein composition and high density lipoprotein cholesteryl ester metabolism. J. Clin Invest. 84:129-137. 